\title{
NILAI PEMBENTUK KARAKTER KEBANGSAAN PADA BUDAYA LOKAL KEE'RJA BANYAU
}

\author{
Fusnika, Debora Korining Tyas \\ Program Studi Pendidikan Pancasila dan Kewarganegaraan STKIP Persada Khatulistiwa Sintang \\ Jl. Pertamina Km 4 Sengkuang Sintang Kalimantan Barat \\ email:fusnika804@gmail.com
}

\begin{abstract}
This study aimed to provide an overview of the values that have been constructed the national character which found in the local culture of Kee'rja Banyau. The method used qualitative with a case study approach, data collected through observation, interviews, documentation. The findings indicate that local cultural values such as Kee'rja Banyau could be a source of maintaining the social integrity of a society which later became the forerunner of the embedded philosophy of life as part of the national identity. This is because in the local there are some national character values such as tolerance, friendliness or communicative, caring for the environment, social care and responsibility.
\end{abstract}

Keywords: Kee 'rja Banyau, Gotong royong, National character, local culture

\begin{abstract}
Abstrak: Kajian ini bertujuan untuk memberikan gambarantentang nilai-nilai pembentuk karakter kebangsaan yang terdapat pada budaya lokal Kee'rja Banyau. Metode yang digunakan yaitukualitatif dengan pendekatan studi kasus, pengumpulan data melalui observasi, wawancara, dokumentasi. Temuan yang ada menunjukan bahwa nilai budaya lokal seperti Kee 'rja Banyau dapat berfungsi sebagai sumber mempertahankan integritas sosial suatu masyarakat yang kemudian menjadi cikal bakal tertanamnya falsafah kehidupan sebagai bagian dari jatidiri bangsa. Hal ini dikarenakan dalam budaya lokal Kee'rja Banyau terdapat nilai karakter kebangsaan seperti toleransi, bersahabat atau komunikatif, peduli lingkungan, peduli sosial dan tanggungjawab.
\end{abstract}

Kata Kunci: Kee 'rja Banyau, Gotong royong, Karakter Kebangsaan, Budaya Lokal

Kondisi bangsa Indonesia pada saat ini sedang mengalami krisis identitas yaitu lunturnya nilai-nilai karakter kebangsaan seperti nilai perjuangan, semangat, kebersamaan atau gotong royong, kepedulian atau solidaritas, sopan santun, serta nilai persatuan dan kesatuan. Sebagaimana yang diungkapkan oleh Kurniawan (2013:29) karakter merupakan nilai-nilai perilaku manusia yang berhubungan dengan Tuhan Yang Maha Esa, diri sendiri, sesama manusia, lingkungan, dan kebangsaan yang terwujud dalam pikiran, sikap, perasaan, perkataan, dan perbuatan berdasarkan norma-norma agama, hukum, tata krama, budaya dan adat istiadat.

Pembentukan karakter kebangsaan bukanlah hal yang mudah namun juga bukan suatu hal yang mustahil untuk dilakukan, suatu bangsa akan sangat mungkin untuk bisa berkarakter ketika ada langkah gerak yang diupayakan untuk mewujudkannya. Pembangunan karakter kebangsaan adalah suatu proses atau usaha yang dengan sengaja dilakukan dengan tujuan untuk membina, memperbaiki dan membentuk tabiat, watak, sifat kejiwaan, akhlak, masyarakat sehingga menunjukan perbuatan dan tingkah laku yang sesuai dengan nilai-nilai yang berlaku di masyarakat terlebihnya mencerminkan perilaku yang mengamalkan nilai-nilai Pancasila.Upaya penanaman karakter kebangsaan ini sangat sesuai dengan Visi Pembangunan Nasional Indonesia yang berbunyi: "Mewujudkan Indonesia sebagai bangsa yang tangguh, kompetitif, berakhlak mulia, bermoral, berbudi luhur, bertoleransi, bergotong royong, berjiwa patriotik, berkembang dinamis dan berorientasi IPTEK yang dijiwai oleh iman dan taqwa kepada Tuhan Yang Maha Esa berdasarkan 
Pancasila." (Renstra Pembangunan Jangka Panjang Nasional Tahun 2005-2025; UU RI Nomor 17 Tahun 2007).

Sementara itu, nilai karakter yang saat ini paling banyak mendapatkan sorotan akan pergeserannya adalah nilai gotong royong. Hal ini dapat dilihat dari meningkatnya intensitas masyarakat untuk bersikap lebih individualis ketika menjalankan sebuah kegiatan.Padahal, dalam gotong royong terkandung nilai-nilai yang dapat membentuk suatu bangsa menjadi berkarakter. Nilai-nilai tersebut yaitu kebersamaan, kekeluargaan dan persaudaraan, keadilan, sukarela, tanggung jawab dan tolong menolong. Peran aktif setiap individu masyarakat serta adanya persatuan dan kesatuan di dalam kehidupan dan lingkungan masyarakat. Gotong royong sesungguhnya bukan hal yang asing lagi untuk kita bicarakan, karena gotong royong sendiri merupakan budaya yang sangat lekat dan menjadi ciri khas bangsa Indonesia. Budaya gotong royong merupakan budaya nenek moyang bangsa Indonesia yang turun temurun dijadikan sebuah kebiasaan yang menjadi pemersatu dalam kehidupan bermasyarakat, bahkan gotong royong menjadi kekuatan besar bangsa Indonesia dalam melawan penjajah dan meraih kemerdekaan.

Namun kenyataannya, banyak kalangan masyarakat yang sudah melupakan dan tidak menyadari bahwa Indonesia merdeka karena kerja sama dan gotong royong masyarakat terdahulu melawan penjajah. Budaya gotong royong dari masa ke masa dan setiap harinya semakin hilang dalam kehidupan bangsa Indonesia, semakin lama semakin kuat pengaruh budaya Barat dengan menghadirkan individualisme dan liberalisme dalam kehidupan bangsa Indonesia. Pada masa ini budaya gotong royong sudah mulai hilang tidak hanya terjadi di kalangan masyarakat kota saja, di masyarakat pedesaan sekalipun sudah mulai melupakan budaya gotong royong (kee'rja banyau).

Dalam naskah akademik Pengembangandan Pendidikan Budaya dan Karakter Bangsa, Kementerian Pendidikan Nasional telah merumuskan 18 nilai karakter bangsa yang dikembangkan dan ditanamkan kepada generasi muda bangsa Indonesia. Adapun ke-18 nilai untuk pendidikan budaya dan karakter bangsa dapat dilihat pada tabel 1 .

Sementara itu, konsep mengenai budaya gotong royong juga terdapat dalam budaya lokal masyarakat Ketungau Hilir Kabupaten Sintang Kalimantan Barat. Istilah yang digunakan adalahKee'rja banyau.Namun sangat disayangkan pula saat ini masyarakat juga banyak yang kurang memahami konsep tersebut.

Maka dari itu, kajian atas konten ini sangat perlu untuk dilakukan dengan titik utama menggali nilai-nilai pembentuk karakter bangsa yang terdapat dalam budaya lokal Kee'rja Banyau. Mengingatbahwa menghidupkan kembali nilai-nilai yang terdapat dalam Kee'rja banyaudi dalam kehidupan bermasyarakat dapat menjadi langkah gerak dalam melakukan pembangunan di bidang lingkungan kemasyarakatan.

\section{METODE}

Kajian ini menggunakan metode deskriptif kualitatif dengan jenis studi kasus. Metode ini dipilih berdasarkan permasalahan yang muncul dari adanya suatu kasus yang terjadi. Subjek dalam kajian ini adalah masyarakat di Desa Sungai Deras Kecamatan Ketungau Hilir Kabupaten Sintang Provinsi Kalimantan Barat. Objek pada kajian ini adalah pembentukan karakter kebangsaan melalui tradisi budaya lokal yang dikenal dengan istilah kee'rja banyau.

Penentuan subjek dan objek kajian secara purposive dan bersifat Snowball sampling. Jumlah sampel disesuaikan dengan kebutuhan kajian. Berdasarkan pertimbangan peneliti, maka jumlah subjek masyarakat satu desa yang ada di kecamatan Ketungau Hilir Kabupaten Sintang Provinsi Kalimantan Barat. Jumlah Subjek yang direncanakan pada tahap awal sejumlah 5 orang dan akan bertambah sesuai dengan keperluan sampel jenuh. Subjek dipilih menggunakan teknik snowbal sampling atau sampel jenuh, dimana jumlah subjek kajian cenderung bertambah berdasarkan keperluan.

Adapun kriteria penentuan subjek kajian diantaranya: menguasai dan memahami budaya lokal yang disebut dengan istilah kee'rja banyau (gotong royong). Sumber data diperoleh dari Kepala Desa, Kepala Suku, Warga Desa. Dalam kajian kualitatif teknik pengumpulan data yang digunakan adalah observasi, wawancara dan dokumentasi berupa, foto dan video aktivitas warga dalam gotong royong (kee'rja banyau) dalam pembentukan karakter kebangsaan. Tahapan pengumpulan data terdiri dari 3 yakni tahap perencanaan, tahap pelaksanaan dan tahap 
Tabel 1. Deskripsi Nilai untuk Pendidikan Budaya dan Karakter Bangsa

\begin{tabular}{|c|c|}
\hline No Nilai & Deskripsi \\
\hline 1. Religius & $\begin{array}{l}\text { Sikap dan perilaku yang patuh dalam melaksanakan ajaran agama yang dianut nya, toleran } \\
\text { terhadap pelaksanaan ibadahagama lain, dan hidup rukun dengan pemeluk agama lain }\end{array}$ \\
\hline 2. Jujur & $\begin{array}{l}\text { Perilaku yang didasarkan pada upayamenjadikan dirinya sebagai orang yangselalu dapat } \\
\text { dipercaya dalam perkataan,tindakan, dan pekerjaan. }\end{array}$ \\
\hline 3. Toleransi & $\begin{array}{l}\text { Sikap dan tindakan yang menghargaiperbedaan agama, suku, etnis, pendapat,sikap, dan } \\
\text { tindakan orang lain yang berbeda dari dirinya. }\end{array}$ \\
\hline 4. Disiplin & Tindakan yang menunjukkan perilakutertib dan patuh pada berbagai ketentuandan peraturan. \\
\hline 5. KerjaKeras & $\begin{array}{l}\text { Perilaku yang menunjukkan upaya sungguh-sungguh dalam menghadapi berbagaihambatan } \\
\text { belajar dan tugas serta menyelesaikan tugas dengan sebaik-baiknya. }\end{array}$ \\
\hline 6. Kreatif & $\begin{array}{l}\text { Berpikir dan melakukan sesuatu untukmenghasilkan cara atau hasil baru darisesuatu yang } \\
\text { telah dimiliki. }\end{array}$ \\
\hline 7. Mandiri & $\begin{array}{l}\text { Sikap dan perilaku yang tidak mudahtergantung pada orang lain dalam menyelesaikan tugas- } \\
\text { tugas. }\end{array}$ \\
\hline 8. Demokrasi & $\begin{array}{l}\text { Cara berpikir, bersikap, dan bertindakdemokratis yang menilai sama hak dan kewajibandirinya } \\
\text { dan orang lain. }\end{array}$ \\
\hline $\begin{array}{l}\text { 9. Rasa ingin } \\
\text { tahu }\end{array}$ & $\begin{array}{l}\text { Sikap dan tindakan yang selalu berupayauntuk mengetahui lebih mendalam danmeluas dari } \\
\text { sesuatu yang dipelajarinya,dilihat, dan didengar. }\end{array}$ \\
\hline $\begin{array}{l}\text { 10. Semangat } \\
\text { Kebangsaan }\end{array}$ & $\begin{array}{l}\text { Cara berpikir, bertindak, dan berwawasanyang menempatkan kepentingan bangsadan negara } \\
\text { di atas kepentingan diri dankelompoknya. }\end{array}$ \\
\hline 11. CintaTanah & $\begin{array}{l}\text { Cara berpikir, bersikap, dan berbuat yangmenunjukkan kesetiaan, kepedulian, } \\
\text { danpenghargaan, } \\
\text { yang tinggi terhadap bahasa,lingkungan fisik, sosial, budaya, ekonomi,dan politik bangsa. }\end{array}$ \\
\hline 12. Menghargai & $\begin{array}{l}\text { Sikap dan tindakan yang mendorongdirinya untuk menghasilkan sesuatu yangberguna } \\
\text { bagi } \\
\text { masyarakat, dan mengakui,serta menghormati keberhasilan oranglain. }\end{array}$ \\
\hline $\begin{array}{l}\text { 13. Bersahabat/ } \\
\text { Komunikatif }\end{array}$ & $\begin{array}{l}\text { Tindakan yang memperlihatkan senang berbicara, bergaul, dan bekerja sama/berkomunikatif } \\
\text { dengan orang lain. }\end{array}$ \\
\hline 14. Cinta damai & $\begin{array}{l}\text { Sikap, perkataan, dan tindakan yang menyebabkan orang lain merasa senang danaman atas } \\
\text { kehadirannya. }\end{array}$ \\
\hline $\begin{array}{l}\text { 15. Gembar } \\
\text { membaca }\end{array}$ & $\begin{array}{l}\text { Kebiasaan menyediakan waktu untukmembaca berbagai bacaan yang memberikan kebajikan } \\
\text { bagi dirinya. }\end{array}$ \\
\hline $\begin{array}{l}\text { 16. Peduli } \\
\text { lingkungan }\end{array}$ & $\begin{array}{l}\text { Sikap dan tindakan yang selalu berupayamencegah kerusakan pada lingkungan di sekitarnya } \\
\text { dan mengembangkanupaya-upaya untuk memperbaiki kerusakan alam yang sudah terjadi. }\end{array}$ \\
\hline 17. Peduli sosial & $\begin{array}{l}\text { Sikap dan tindakan yang selalu inginmemberi bantuan pada orang lain danmasyarakat yang } \\
\text { membutuhkan. }\end{array}$ \\
\hline $\begin{array}{l}\text { 18. Tanggung } \\
\text { jawab }\end{array}$ & $\begin{array}{l}\text { Sikap dan perilaku seseorang untukmelaksanakan tugas dan kewajibannya,yang seharusnya } \\
\text { dia lakukan, terhadap dirisendiri, masyarakat, lingkungan (alam,sosial, dan budaya), negara, } \\
\text { dan Tuhan Yang Maha Esa. }\end{array}$ \\
\hline
\end{tabular}

analisis data. Tahap Perencanaan dimulai dari mengurus perijinan dan administrasi terkait dengan rencana pelaksanaan kajian. Pelaksanaan kajiant erhadap pembentukan karakter kebangsaan melalui budaya lokal Kee'rja Banyau yang akan dilaksanakan dalam kajian dan menyusun 
instrumen kajian yang berupa panduan wawancara, panduan observasi dan dokumentasi.

Pada tahap pengumpulan data, peneliti terjun kemasyarakat untuk melakukan wawancara mendalam, observasi dan dokumentasi kepada responden terkait dengan pembentukan karakter kebangsaan melalui budaya lokal Kee'rja Banyau. Tahap selanjutnya yakni tahap analisis data. Setelah selesai proses pengumpulan data, diperoleh sejumlah data kualitatif. Analisis dan pengolahan data berpedoman pada data yang terkumpul dan pertanyaan kajian. Data kualitatif dari kajian ini yaitu hasil pengamatan dan wawancara yang dilakukan pada warga Desa Sungai Deras Kecamatan Ketungau Hilir Kabupaten Sintang Provinsi Kalimantan Barat dengan pembentukan karakter kebangsaan melalui budaya lokal Kee'rja Banyau, data yang terkumpul dianalisis secara deskriptif.

Pada tahapan analisis data, kajian kualitatif bersifat induktif, bahwa semua simpulan dibentuk dari semua informan yang diperoleh dari lapangan. Teknik analisis data yang digunakan adalah teknik analisis data deskriptif kualitatif memanfaatkan persentase hanya merupakan langkah awal dari proses analisis data (Arikunto, 2000: 352). Dalam proses selanjutnya analisis data kualitatif terdiri dari empat alur kegiatan yang terjadi secara bersamaan, yaitu catatan lapangan, pengumpulan informasi, penyajian informasi, dan penarikan kesimpulan (Miles dan Huberman, 1992:16-21). Analisis data dilakukan secara deskriptif (descriptiveanalysis).

\section{HASIL DAN PEMBAHASAN}

\section{Pembentukan Karakter Kebangsaan yang terdapat pada Budaya Lokal Kee'rja Banyau}

Karakter memiliki peran yang sangat penting untuk membangun suatu bangsa yang kuat, nilai karakter itu sangat tinggi nilainya, seperti yang diungkapkan oleh Saptono (2011:16) bahwa karakter itu lebih tinggi nilainya dari pada intelektualitas. Jadi sebanyak apapun orang-orang yang berintelektualitas di suatu bangsa kalau tidak didukung oleh manusia-manusia yang memiliki karakter semuanya tidak akan berjalan baik. Pembentukan karakter yang terdapat pada budaya lokal kee'rja banyau mengandung nilai toleransi yaitu tercermin pada sikap dan tindakan dari warga desa yang menghargai perbedaan agama, suku, etnis dan tindakan orang lain yang berbeda dari dirinya.

Warga di Desa Sungai Deras Kecamatan Ketungau Hilir Kabupaten Sintang Provinsi Kalimantan Barat seperti yang kita ketahui mayoraitas beragama Kristen dan masyarakat muslim juga ada beberapa kepala keluarga. Masyarakat non muslim dan masyarakat muslim juga turut berpartisipasi dalam bentuk apapun baik dalam keagamaan maupun pembangunan tempattempat ibadah dan sudah terwujudkan cukup bagus. Landasan yang menjadi dasar kerukunan dan toleransi antar Masyarakat DesaSungai Deras Kecamatan Ketungau Hilir Kabupaten Sintang Provinsi Kalimantan Barat adalah Kearifan lokal (budaya) tersebut yang merupakan landasan utama yang mengandung makna positif. Ungkapan lokal tersebut adalah kee'rja banyau yang diwariskan dari generasi ke generasi yang akan datang.

Peduli sosial, peduli lingkungan dan bertanggungjawab yang melatarbelakangi keharmonisan pada warga di Desa Sungai Deras Kecamatan Ketungau Hilir Kabupaten Sintang Provinsi Kalimantan Barat dengan adanya budaya lokal yang disebut dengan kee'rja banyau (gotong royong) yang dilakukan oleh warga di Desa Sungai Deras Kecamatan Ketungau Hilir Kabupaten Sintang Provinsi Kalimantan Barat dalam bidang pembangunan infrastruktur desa dan pembangunan rumah, jalan antar desa yang dilakukan bersama-sama. Hal tersebut merupakan wujud kebudayaan lokal yang sangat berfungsi sebagai kekuatan terciptanya kerukunan. Oleh karena itu, budaya tersebut perlu dipelihara oleh masyarakat dengan menggalakkan semangat budaya lokal kee'rja banyau (gotong royong)

Pembentukan karakter kebangsaan yang terdapat pada budaya lokal kee'rja banyau di Desa Sungai Deras Kecamatan Ketungau Hilir Kabupaten Sintang Provinsi Kalimantan Barat, terkandung nilai persahabatan dan komunikatif. Tindakan yang memperlihatkan senang bergaul dan bekerja sama atau berkomunikati antar warga Desa Sungai Deras, yang tercermin dalam perilaku saat ada warga sedang mengalami kesulitan atau tertimpa bencana, maka setiap warga memberikan bantuan sesuai dengan kemampuannya.

Selanjutnya pembentukan karakter kebangsaan yang terdapat pada budaya lokal kee'rja banyau di Desa Sungai Deras Kecamatan Ketungau Hilir Kabupaten Sintang 
Provinsi Kalimantan Barat, tercermin sikap peduli sosial dan tanggungjawabdesa yang dianggap kewajiban dari setiap warga. Kegiatan tolong menolong secara spontan dari para warga sebagai anggota diberikan pada keluarga yang mengalami kedukaan dan musibah lainnya.Karakter merupakan salah satu hal yang sangat penting untuk dimiliki oleh setiap orang, karena karakter merupakan hal yang tidak bisa dipisahkan dari kehidupan seorang karena pada dasarnya karakter telah ada sejak seseoarang mulai mengenal kehidupan dan melekat pada setiap orang, baik itu karakter yang baik ataupun karakter yang buruk.

Orang yang memiliki karakter yang baik akan sangat berbeda dengan orang yang memiliki karakter buruk, cenderungnya orang yang memiliki karakter yang kuat mereka akan menjadi orang yang kuat dalam menghadapi persoalan atau permasalahan hidup, sehingga mereka mempunyai pandangan dan masa depan yang cerah, namun sebaliknya seseorang yang memiliki karakter yang buruk, mereka cenderung menjadi orang yang pasrah dan selalu merasa permasalahan yang terjadi dan dihadapi merupakan hal yang sangat buruk baginya dan pada akhirnya orang yang memiliki karakter yang buruk masa depannya juga cenderung mengarah ke hal-hal yang suram.

Di Setiap daerah di Indonesia sudah barang tentu memiliki keunggulan-keunggulan dalam hal budaya, yang apabila diinventarisir akan menjadikan kekayaan bangsa yang tidak ternilai. Bangsa Indonesia merupakan bangsa yang besar dan plural dengan beragamnya etnik dan budaya yang ada di dalamnya. Harus diyakini bahwa setiap etnik memiliki nilai-nilai budaya lokal masingmasing. Dalam konteks akademik nilai-nilai budaya lokal suatu masyarakat bercirikan: "(1) berdasarkan pengalaman, (2) teruji setelah digunakan berabad-abad, (3) dapat beradaptasi dengan kultur kini, (4) dalam praktek keseharian masyarakat dan lembaga (5) lazim dilakukan oleh individu dan masyarakat secara keseluruhan (6) bersifat dinamis dan terus berubah, dan (7) sangat terkait dengan sistem kepercayaan". (Al Wasilah,2009. 51)

Manusia adalah makhluk social, saling membutuhkan satu dengan yang lainnya agar mampu bertahan hidup dan berkembang layaknya manusia, begitu juga dengan warga Desa Sungai
Deras Kecamatan Ketungau Hilir Kabupaten Sintang Provinsi Kalimantan Baratsaling menolong satu dengan yang lainnya. Setiap warga desa saling melakukan interaksi yang sangat baik, interaksiantar individu dengan individu atau interaksi individu dengan masyarakat dan antar berbagai kelompok masyarakat yang ada di lingkungan desa.

Gotong royong (kee'rja banyau) adalah salah satu wujud kegiatan sosial (interaksi) yang menjadi ciri khas bangsa Indonesia dari zaman dahulu. Panjaitan (2016:36) mendefinisikan gotong royong adalah kerjasama sukarela dan setara dalam semangat persaudaraan, bantu membantu dan tolong menolong untuk kebaikan bersama. Sedangkan menurut Koentjaraningrat (2015:73) gotong royong adalah aktivitas tolong menolong antara tetangga, atau antara kaum kerabat dalam masyarakat desa kecil.Selanjutnya, Rahman (2016:90) mengatakan gotong royong adalah kegiatan yang dilakukan secara bersama-sama dan bersifat sukarela dengan tujuan agar kegiatan yang dikerjakan dapat berjalan dengan lancar, mudah dan ringan.Merujuk pada berbagai teori tersebut, nilai-nilai yang terdapat pada budaya lokal kee'rja banyau adalah kebersamaan, kekeluargaan dan persaudaraan, keadilan, sukarela atau keikhlasan, tanggung jawab, tolong menolong, persatuan dan kesatuan antar warga.

\section{SIMPULAN}

Pembentukan karakter kebangsaan yang terdapat pada budaya lokal kee'rja banyauwarga di Desa Sungai Deras Kecamatan Ketungau Hilir Kabupaten Sintang Provinsi Kalimantan Barat mengandung nilai toleransi, nilai bersahabat atau komunikatif, nilai peduli lingkungan, nilai peduli sosial dan nilaitanggungjawab.Nilai budaya lokal kee'rja banyauwarga Desa Sungai Deras Kecamatan Ketungau Hilir Kabupaten Sintang Provinsi Kalimantan Barat sebagai salah satu budaya khas bangsa Indonesia yang sarat akan nilai-nilai luhur Pancasila sebagai sumbernya. nilai budaya lokal, dapat menjadi pemelihara dan berfungsi mempertahankan integritas sosial suatu masyarakat dan akan tertanam falsafah kehidupan sebagai bagian dari jatidiri bangsa 


\section{DAFTAR RUJUKAN}

Arikunto Suharsimi. 2005. Prosedur Kajian Suatu Pendekatan Praktik, Jakarta: Rineka Cipta.

Kurniawan, S. 2013. Pendidikan Karakter Konsepsi dan Implementasinya Secara Terpadu Di Lingkungan Keluarga, Sekolah, Perguruan Tinggi, dan Masyarakat. Yogyakarta. Ar-Ruzz Media.
Miles, Mattew B dan Hubermen, Michael. 1992.Analisa Data Kualitatif: Buku SumberTentang Metode Baru, Terjemahan Tjetjep Rohendy (2007), Jakarta: UI Press.

Republik Indonesia. 2005. Renstra Pembangunan Jangka Panjang Nasional Tahun 2005-2025; UU RI Nomor 17 Tahun 2007 